\title{
Thermal analysis in foundry technology
}

\section{Part 2. TG-DTG-DSC, TG-MS and TG-IR study of the new class of polymer binders BioCo}

\author{
Beata Grabowska ${ }^{1}$ Krzysztof Hodor ${ }^{2} \cdot$ Karolina Kaczmarska $^{1} \cdot$ Artur Bobrowski $^{1}$. \\ Żaneta Kurleto-Koziot $^{1} \cdot$ Carolin Fischer $^{3}$
}

Received: 1 December 2016/Accepted: 23 May 2017/Published online: 6 June 2017

(C) The Author(s) 2017. This article is an open access publication

\begin{abstract}
In this study, a polymer composition of poly (acrylic acid) and dextrin (PAA/D) cross-linked with microwave radiation, belonging to the new BioCo group of environmentally friendly foundry binders, was subjected to thermal analysis (TG-DTG-DSC, TG-MS, TG-IR) in a temperature range of $20-600{ }^{\circ} \mathrm{C}$. A thermal analysis of PAA/D compositions enables the determination of a temperature range at which the composition is not susceptible to thermal degradation and thus does not lose its binding properties. The study showed that the process of thermal degradation of PAA/D is complex and multi-stage (TGDTG-DSC). Within a temperature range of $20-250{ }^{\circ} \mathrm{C}$, physical and chemical changes take place associated with the evaporation of the water fraction of the solvent $\left(20-100{ }^{\circ} \mathrm{C}\right)$, next with the evaporation of the water hydration and finally with intermolecular dehydration reactions $\left(100-250^{\circ} \mathrm{C}\right)$. Above a temperature of $300{ }^{\circ} \mathrm{C}$, the decomposition of the polymer chains takes places, and thereafter, the intensive degradation of PAA/D occurs together the creation of gaseous substances, primarily low molecular weight inorganic $\left(\mathrm{CO}_{2}, \mathrm{H}_{2} \mathrm{O}, \mathrm{CO}\right)$ and organic compounds, including methane (TG-IR, TG-MS).
\end{abstract}

Beata Grabowska

beata.grabowska@agh.edu.pl

1 Faculty of Foundry Engineering, AGH - University of Science and Technology, Reymonta 23, 30059 Krakow, Poland

2 Netzsch Instrumenty Sp. zo.o., ul. Halicka 9, 31-036 Kraków, Poland

3 NETZSCH-Gerätebau GmbH BU Analyzing and Testing, Selb, Germany
Keywords Polymer binders · Foundry sands - Thermal degradation $\cdot$ TG-DSC $\cdot$ TG-IR $\cdot$ TG-MS

\section{Introduction}

The polymer materials, solvents and organic hardeners used in foundry sands are the main source of hazardous compounds emitted by these sands. Emissions of such compounds may begin to take place as early as the mass preparation stage, when volatile organic substances, mainly solvents, are released. The majority of these gaseous substances, however, arise when the sand comes into contact with the molten metal, as high temperatures lead to thermal degradation of their organic components [1-3].

The level of gas emissions from foundry sands becomes relevant in the context of maintaining workplace safety at the foundry, as well as having an influence on the final quality of the cast. Techniques which make use of organic components containing phenyls, amines and sulphurs are potentially harmful. The impact of the amines released during the hardening of the sand, and of aromatic hydrocarbons generated during the degradation of the organic mass is not neutral for environment [4-6]. Moreover, the technological and economic aspects must be taken into consideration, as the gasses released during degradation (including $\mathrm{SO}_{2}$ ) may enter into undesirable reactions at the mould-foundry sand interface, leading to significant casting flaws, including deterioration of the state of the cast's surface $[7,8]$. Foundry sands containing polymer BioCo binders are characterised by satisfactory mechanical durability after hardening [9]. The use of these new BioCo binders in the form of polymer compositions in the foundry sands ensures that a mould for casting iron can be achieved which meets the requirements both in terms of quality and 
of durability for the selected type of iron, while also creating a cast which does not present difficulties during removal from the mould. The casts are free of flaws, and the results of durability tests conducted on samples of casts confirm that ductile cast iron is obtained. BioCo binders in the form of aqueous compositions of poly(acrylic acid) polymers and modified polysaccharide (dextrin, carboxymethyl starch) are environmentally friendly binding materials (for sand grains $\mathrm{SiO}_{2}$ ). These materials include polymer compositions of poly(acrylic acid) and dextrin (PAA/D). BioCo binders do not contain harmful substances and are soluble in water. It has been proven that in the field of microwave radiation under via adsorption goes the transient formation of networks as result of hydrogen bonds. Hydrogen bonds are mainly responsible for upholding cross-linked structures in the system bindersand grains. Under the influence of microwave radiation at increased temperatures, the cross-linking reaction occurs by the PAA dehydration and anhydride bonds are formed (Fig. 1) [10, 11].

The benzene, toluene, ethylbenzene and xylenes (BTEX) emission levels which take place when the molten cast iron is poured into the mould of foundry sands containing BioCo binder remain low, as indicated by experimental analysis conducted in semi-technical conditions [9].

However, in order to fully understand the process of occurrence of gaseous substances when the molten metal comes into contact with the mould, it is essential to understand the degradation process of the binder itself. It can be assumed that the thermal degradation process of the binder takes place in anaerobic conditions, although in moulds of a non-homogeneous structure a certain amount of trapped air may be found. Additionally, the interior of the mould into which the molten metal is poured is filled with air. Therefore, the thermal degradation of the binder takes place with the limited participation of oxygen, and the mechanism for the degradation reaction may be considered to be mixed [4, 12, 13]. Moreover, at a distance of 5-30 $\mathrm{mm}$ from the cast-mould interface, a temperature of between 300 and $600{ }^{\circ} \mathrm{C}$ is maintained for approximately $1 \mathrm{~h}$. This temperature range may be conducive to many reactions, mainly to degradation, including cyclisation and dehydrogenation [12]. Moreover, the dynamic process of the emission of gaseous products of degradation and their increased pressure on the mould may also cause localised increases in pressure which are conducive to degradation reactions. In such conditions, low molecular weight compounds arising from partial degradation and also alkyl radicals undergo further changes. These reactions may thus lead to the occurrence of hydrocarbons, including aromatic hydrocarbons [14].

There are several methods of measurement related to qualitative and quantitative analysis of gasses emitted during the process of pouring molten metal into the mould [15]. Some of these methods permit the amount and kinetics of the gasses emitted to be determined and allow for the analysis of aromatic hydrocarbons, including benzene, toluene, ethylbenzene and xylenes (BTEX), released when the molten metal is poured into the mould [2]. During this pouring process, gaseous substances are released from the mould and conducted through the discharge system, next through the drying system and finally onto an adsorber (activated carbon) where the adsorption of the organic compounds contained in the gasses flowing through the
Fig. 1 Cross-linking hydrogen bonds in the binder-sand grains system [10]

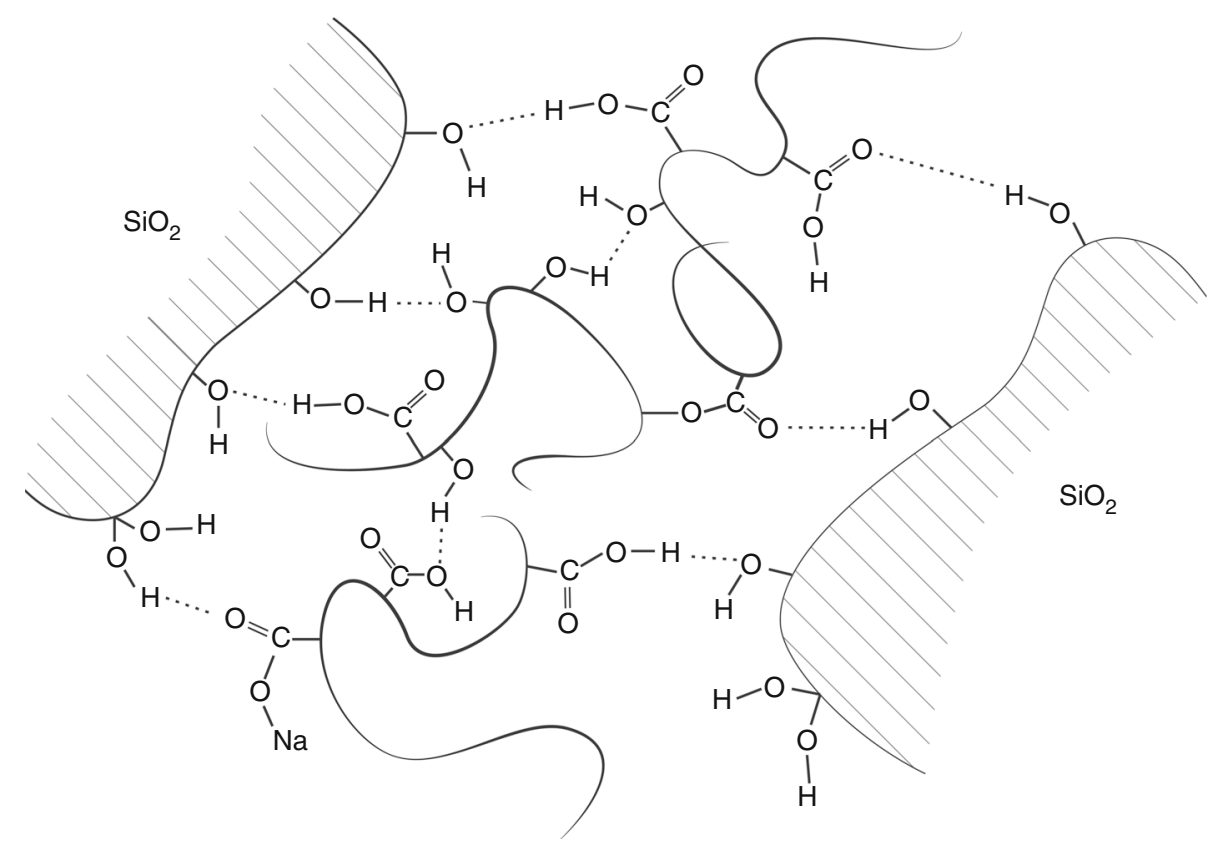


system takes place [16]. This adsorption takes place successively in two separate layers, a measuring layer and a control layer. The control layer serves to capture those gasses which were not adsorbed by the first measuring layer. The gasses which are adsorbed by the activated carbon of the measuring and control layers, after any carbon disulphide $\left(\mathrm{CS}_{2}\right)$ has been extracted, are subjected to analysis by gas chromatography (GC) using a flame ionisation detector (FID).

In this study, an analysis of the thermal degradation process of polymer binders in the form of a composition of PAA/D was conducted, based on the literature regarding the degradation of polyacrylic acid polymers and polysaccharides, as well as on the results of the authors' own research (TG-DSC, TG-MS, TG-IR) [3, 17-21]. To determine the values of degradation temperatures and the thermal effects which took place during heating of composition samples, TG and DSC thermal analysis (TA) methods were used. The results of TG-DSC analysis for polymer compositions containing poly(acrylic acid) and polysaccharides have already been presented in the first part of this publication [13]. In this work, an attempt was made to identify the thermal degradation process of the PAA/D polymer composition based on extended TGDTG-DSC thermal analysis, taking into consideration volatile products of degradation using two coupled techniques; TG-MS - thermogravimetry directly coupled to mass spectrometry and TG-IR - thermogravimetry online coupled to Fourier transform infrared spectroscopy (FTIR). The data obtained are also crucial in regard to the optimisation of conditions for cross-linking with microwave radiation and for conventional heating methods for the $\mathrm{PAA} / \mathrm{D}$ composition, as well as in the context of the processes taking place in the cast-mould complex associated with the emission of gaseous products and their impact on the quality of the cast.

\section{Experimental}

\section{Material}

Thermal analysis involved polymer composition of PAA/D cross-linked with microwave radiation. Their characterisation and cross-linking condition PAA/D are provided in Table 1.

\section{Thermal examinations}

The NETZSCH model STA 449 F3 Jupiter $^{\circledR}$ simultaneous thermal analyser can be used to measure the mass change and transformation energetics of a wide range of materials. The top-loading STA can be equipped with
Table 1 Characteristics of compositions and their cross-linking parameters

\begin{tabular}{llc}
\hline Polymer & Composition & Hardening conditions \\
\hline PAA/D & 62\% aqueous solution of & Microwave device: \\
& poly(acrylic acid) (PAA, & RM 2001 Pc, \\
& 100,000 $\left.\mathrm{g} \mathrm{mol}^{-1}, \mathrm{BASF}\right)$ and & Plazmatronica \\
& dextrin $(\mathrm{D}$, modified potato & Microwave power of \\
& starch, Fluka), in a mass ratio & $800 \mathrm{~W}$ \\
$7: 8, \mathrm{pH} 1.5$ & Frequency of \\
& & $2.45 \mathrm{GHz}$ \\
& Microwave action \\
& time: $60 \mathrm{~s}$ \\
& Temperature inside the \\
& & device: $100{ }^{\circ} \mathrm{C}$ \\
\hline
\end{tabular}

various easily exchangeable TG, TG-DTA or true TGDSC sensors and with different furnaces to accommodate different temperature ranges. The system employed for this work was equipped with a silicon carbide furnace capable of operation from room temperature to $1550{ }^{\circ} \mathrm{C}$. The system is vacuum tight, allowing measurements to be conducted under pure inert, reducing or oxidising atmospheres. Heating rates of up to $50 \mathrm{~K} \mathrm{~min}^{-1}$ can be employed and the digital resolution of the balance is $1 \mu \mathrm{g}$ digit $^{-1}$. Data acquisition and evaluation, as well as instrument control, are carried out using an MS-Windows software package. The software allows the computation of the rate of mass change, mass change steps, onset and peak temperatures, inflection points and peak area integration.

The Thermo-Microbalance NETZSCH TG 209 F1 Iris $^{\circledR}$ with an effective resolution of $0.1 \mu \mathrm{g}$ enables highly precise measurements under pure gas atmospheres from ambient temperatures up to $600{ }^{\circ} \mathrm{C}$. Internal mass flow controllers (MFC) guarantee a highly precise gas flow adjustment of three different gases.

Data exchange between NETZSCH PROTEUS software and Bruker OPUS software is done online during the measurement. This guarantees simultaneous start and stop of the measurement as well as data exchange during the measurements.

The IR system is a commercial system of the company Bruker (Tensor 27) with a special external gas cell for TG coupling (TG-IR, also available from Bruker). The TG-IR extension is equipped with a separated MCT detector and a gas cell with an optical path length of $123 \mathrm{~mm}$ and an internal volume of $8.7 \mathrm{~mL}$. The transfer time between TG and IR is dependent of the selected gas flow of the TG and covers typically a range of about 15-20 s. However, this time offset is automatically corrected during the evaluation of the TG-FTIR data. 
Table 2 Measurement parameters

\begin{tabular}{|c|c|c|}
\hline Parameters & STA-MS & TG-IR \\
\hline $\begin{array}{l}\text { Temperature } \\
\text { program }\end{array}$ & $40-600{ }^{\circ} \mathrm{C}$ & $\mathrm{RT}-600{ }^{\circ} \mathrm{C}$ \\
\hline Heating rate & $20 \mathrm{~K} \mathrm{~min}^{-1}$ & $20 \mathrm{~K} \mathrm{~min}^{-1}$ \\
\hline Atmosphere & Nitrogen & Nitrogen \\
\hline Flow rate & $70 \mathrm{~mL} \min ^{-1}$ & $40 \mathrm{~mL} \min ^{-1}$ \\
\hline Sample holder & TG-DSC type S & $\begin{array}{c}\text { sample carrier for } \\
\text { corrosive gases }\end{array}$ \\
\hline Crucible & $\begin{array}{l}\text { Platinum with } \\
\text { pierced lids }\end{array}$ & $\mathrm{Al}_{2} \mathrm{O}_{3}(85 \mu \mathrm{L})$ \\
\hline Sample mass & $10.50 \mathrm{mg}$ & $24.43 \mathrm{mg}$ \\
\hline
\end{tabular}

Table 2 presents the collected STA-MS and TG-IR measurement parameters.

\section{Results and discussion}

The results of TG-DSC analysis (in oxygen and oxygenfree atmosphere) for polymer compositions containing poly(acrylic acid) and polysaccharides (polymer binders BioCo) have already been presented in the first part of this publication [13]. In this work (Part 2), an attempt was made to identify the thermal degradation process of the PAA/D polymer composition based on extended TG-DTG-DSC thermal analysis, taking into consideration volatile products of degradation using two coupled techniques; TGMS - thermogravimetry directly coupled to mass spectrometry and TG-IR - thermogravimetry online coupled to Fourier transform infrared spectroscopy (FTIR). The thermal degradation of the binder in the mould takes place with the limited participation of oxygen (conditions

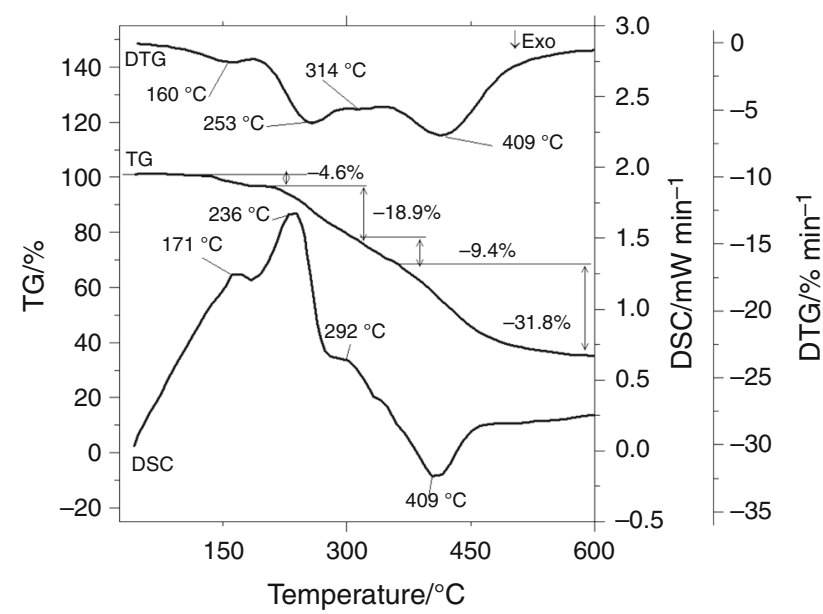

Fig. 2 TG-DTG-DSC curves of PAA/D composition corresponding to the process of pouring the liquid metal/ alloy into a mould). Therefore, this paper presents thermal analysis in oxygen-free conditions.

Figure 2 depicts the temperature-dependent mass change (TG), rate of mass change (DTG) and heat flow rate (DSC) of the polymer mixture PAA/D. In total, four mass loss steps of 4.6, 18.9, 9.4 and $31.8 \%$ were observed. The maximal mass loss rates were observed at the temperatures 156, 257, 314 and $409{ }^{\circ} \mathrm{C}$ which can be seen from the DTG signal. In correlation with the mass loss steps, different energetic effects occurred in the DSC signal. Three overlapping endothermic effects with peak temperatures of 171 , 236 and $292{ }^{\circ} \mathrm{C}$ occurred. The fourth mass loss step correlated with an exothermic peak at $409{ }^{\circ} \mathrm{C}$. The PAA/D degradation mechanism included dehydration, the formation of anhydride-type structures and their decarboxylation, chains scission and depolymerisation. Physically absorbed water was released during the first stage with a small mass loss. The next stages involved anhydride formation and decarboxylation. The last stage during the pyrolysis of PAA/D probably was associated with the release of acrylic acid (depolymerisation), decomposition of polymer chains (poly(acrylic acid), dextrin), or oxidation process of the partially decomposed matter in a wide temperature range, from 400 to $600{ }^{\circ} \mathrm{C}$. Above $400{ }^{\circ} \mathrm{C}$ in nitrogen atmosphere, a carbonaceous residue was generated (a residual mass of $35.3 \%)$ [13, 21, 22].

Information obtained by analysing the TG-DSC curves for the PAA/D composition is presented in Table 3.

Figure 3 presents the most intensive mass numbers as a result of mass spectrometry for PAA/D. The mass numbers $15,16,17$ and 18 showed significant intensity up to $450{ }^{\circ} \mathrm{C}$ and mass number 15 has an additional maximum at $530{ }^{\circ} \mathrm{C}$. Mass numbers 17 and 18 are probably due to the release of radical ${ }^{*} \mathrm{OH}$ and moisture $\left(\mathrm{H}_{2} \mathrm{O}\right)$. The mass numbers 15 and 16 could be due to radical ${ }^{*} \mathrm{CH}_{3}$ and methane $\left(\mathrm{CH}_{4}\right)$. These evolved gases correlate with the mass loss steps three and four.

Figure 4 depicts the mass numbers $41,42,43$ and 44 which were released between 250 and $550{ }^{\circ} \mathrm{C}$ and are

Table 3 Analysis of TG-DSC curves of PAA/D composition in a nitrogen atmosphere

\begin{tabular}{lcll}
\hline Stage & \multicolumn{2}{l}{ Oxygen-free atmosphere } \\
\cline { 2 - 4 } I & $\Delta \mathrm{m} / \%$ & $\begin{array}{l}\text { Temp. of maximum rate of } \\
\text { mass loss } /{ }^{\circ} \mathrm{C}\end{array}$ & $\begin{array}{l}\text { DSC effect } \\
\text { temperature } /{ }^{\circ} \mathrm{C}\end{array}$ \\
\hline II & 4.6 & 156 & endo-171 \\
III & 18.9 & 257 & endo-236 \\
IV & 9.4 & 314 & endo-292 \\
& 31.8 & 409 & exo-409 \\
& \multicolumn{2}{l}{ Remaining sample mass $35.3 \%$} &
\end{tabular}




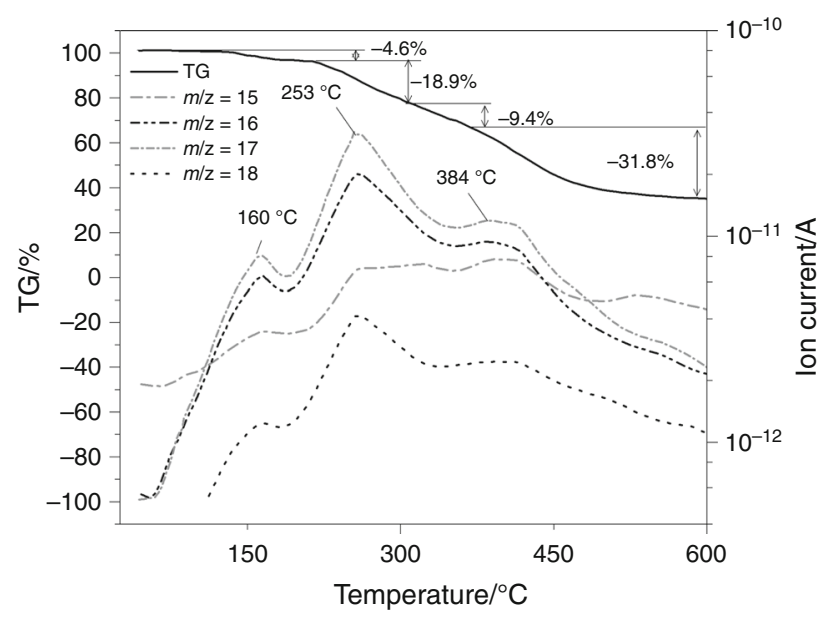

Fig. 3 Temperature-dependent mass change (TG-MS) results of mass spectrometry, ion current for mass numbers: 15 (line $\mathrm{m} / \mathrm{z}=15$ ), $16($ line $\mathrm{m} / \mathrm{z}=16), 17$ (line $\mathrm{m} / \mathrm{z}=17$ ) and 18 (line $\mathrm{m} / \mathrm{z}=18$ ) of PAA/D composition

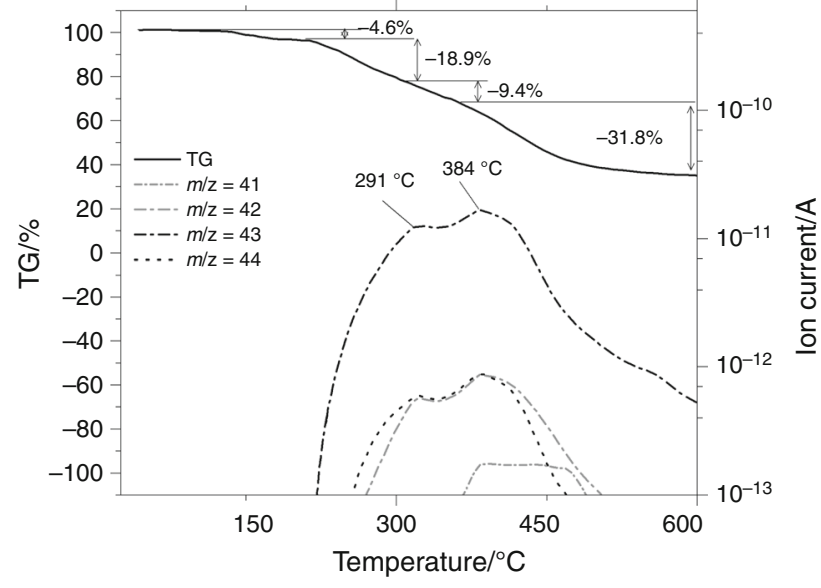

Fig. 4 Temperature-dependent mass change (TG-MS) results of mass spectrometry, ion current for mass numbers: 41 (line $\mathrm{m} / \mathrm{z}=41$ ), 42 (line $m / z=42$ ), 43 (line $m / z=43$ ) and 44 (line $m / z=44$ ) of PAA/D composition

associated with the mass loss steps three and four. Mass number 44 may be identified as carbon dioxide $\left(\mathrm{CO}_{2}\right)$ and 42 - propene $\left(\mathrm{C}_{3} \mathrm{H}_{6}\right)$. The comparison to the NIST Atomic Spectra Database revealed that at $384{ }^{\circ} \mathrm{C}$ propene may be released [23].

The release of the mass numbers 38 and 40 mainly occurred between 350 and $550{ }^{\circ} \mathrm{C}$ and is related to the fourth mass loss step, which can be seen from Fig. 5 .

The release of the mass numbers 78, 92 and 106 mainly occurred between 350 and $550{ }^{\circ} \mathrm{C}$ and is related to the fourth mass loss step, which can be seen from Fig. 6.

In addition, the most probable decomposition products with characteristic $\mathrm{m} / \mathrm{z}$ values [22] are given in Table 4 .

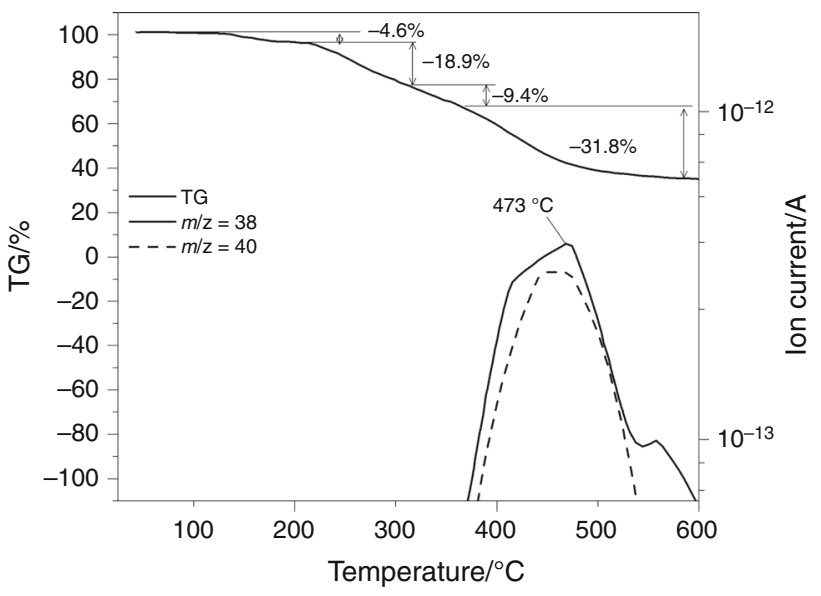

Fig. 5 Temperature-dependent mass change (TG-MS) results of mass spectrometry, ion current for mass numbers: 38 (line $\mathrm{m} / \mathrm{z}=38$ ) and 40 (line $m / z=40$ ) of PAA/D composition

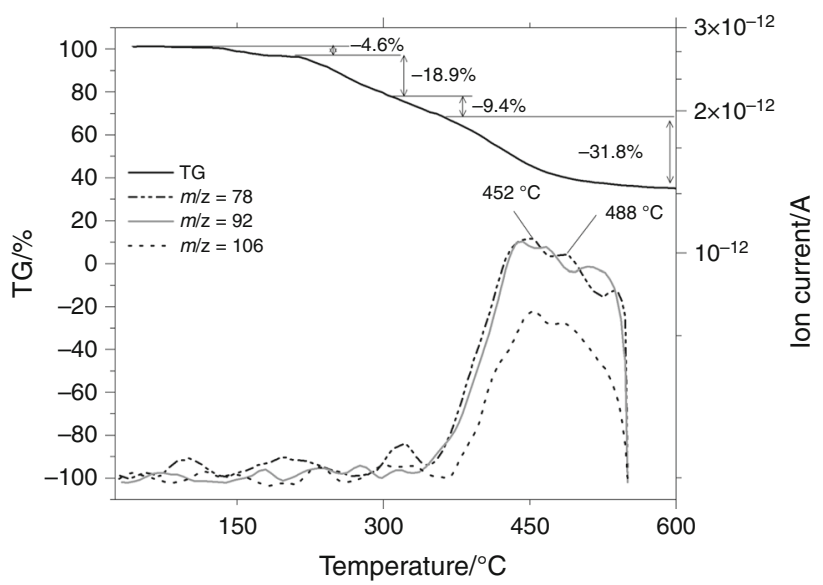

Fig. 6 Temperature-dependent mass change (TG-MS) results of mass spectrometry, ion current for mass numbers: 78 (line $\mathrm{m} / z=78$ ), 92 (line $m / z=92$ ) and 106 (line $m / z=106$ ) of PAA/D composition

Figure 7 shows the TG results of the measurement of the sample in a temperature range from room temperature to $600{ }^{\circ} \mathrm{C}$ in a nitrogen atmosphere with a heating rate of $20 \mathrm{~K} \mathrm{~min}^{-1}$.

TG depicts the relative mass change of the sample PAA/ $\mathrm{D}$, the mass loss rate signal as the first derivative of TGDTG and the Gram-Schmidt trace as the overall IR intensities. Corresponding to the DTG curve, the intensities of the Gram-Schmidt trace increase as soon as a mass loss is detected. It is more or less a mirror image of the DTG curve, and this shows that the gases interact with the infrared beam as soon as they are released and transferred to the gas cell. The Gram-Schmidt signal in contrast is collected based on the individual spectra. Therefore, it is possible that the Gram-Schmidt curve contains a data point which has no corresponding spectrum with the same 
Table 4 Main volatile decomposition products and the corresponding $\mathrm{m} / \mathrm{z}$ ion values with relative intensity regarding the NIST Atomic Spectra Database [23]

\begin{tabular}{|c|c|c|c|}
\hline $\mathrm{m} / \mathrm{z}$ Value & Assignment & Volatile decomposition products & $\begin{array}{l}\text { Temperature range of most } \\
\text { intensive product current } /{ }^{\circ} \mathrm{C}\end{array}$ \\
\hline 15 & $\mathrm{CH}_{3}$ & Radical ${ }^{*} \mathrm{CH}_{3}$ & $150-530$ \\
\hline 16 & $\mathrm{CH}_{4}$ & Methane & $150-450$ \\
\hline 17 & $\mathrm{HO}$ & Radical ${ }^{*} \mathrm{OH}$ & $150-450$ \\
\hline 18 & $\mathrm{H}_{2} \mathrm{O}$ & Water & $150-450$ \\
\hline 38 & $\mathrm{C}_{3} \mathrm{H}_{2}$ & Cyclopropenylidene & $350-550$ \\
\hline 40 & $\mathrm{C}_{3} \mathrm{H}_{4}$ & Cyclopropene methylacetylene & $350-550$ \\
\hline 41 & $\mathrm{C}_{3} \mathrm{H}_{5}$ & Allyl radical & $350-550$ \\
\hline 42 & $\mathrm{C}_{3} \mathrm{H}_{6}$ & Propene & $350-550$ \\
\hline 43 & $\mathrm{C}_{3} \mathrm{H}_{7}$ & Radical propane & $350-550$ \\
\hline 44 & $\mathrm{CO}_{2}$ & Carbon dioxide & $350-550$ \\
\hline 78 & $\mathrm{C}_{6} \mathrm{H}_{6}$ & & $350-550$ \\
\hline 92 & $\mathrm{C}_{7} \mathrm{H}_{8}$ & & $350-550$ \\
\hline 106 & $\mathrm{C}_{8} \mathrm{H}_{10}$ & $\mathrm{CH}_{2} \mathrm{CH}_{3}$ & $350-550$ \\
\hline
\end{tabular}

temperature. Therefore, typically the nearest temperature available spectrum is taken for evaluation of the FTIR data.

Four mass loss steps can be detected comparable to the STA results, with DTG minima at $160,251,315$ and $418{ }^{\circ} \mathrm{C}$. Additional peaks in the Gram-Schmidt curve are visible which are evaluated with the help of two-dimensional spectra. A residual mass of about $25 \%$ can be detected.

Accounting for the trajectories of TG-DTG and GramSchmidt curves (Fig. 7), gas product IR spectra were extracted for a given mass loss (Fig. 8).

In conjunction with an increase in temperature, physical and chemical changes may occur associated with the multistage decomposition of the PAA/D composition. The first loss of mass is related to the evaporation of the water fraction of the solvent, and the next loss is related to the evaporation of the hydration water $\left(100-230^{\circ} \mathrm{C}\right)[24,25]$. The IR spectrum obtained at a temperature of $163{ }^{\circ} \mathrm{C}$ is related to the release of water, which was confirmed by comparing this spectrum with the model IR spectrum for water (library spectrum) (Fig. 9).

During the second loss of mass at $253{ }^{\circ} \mathrm{C}$, water is released, along with $\mathrm{CO}_{2}$. The IR spectrum extracted at a temperature of $253{ }^{\circ} \mathrm{C}$ (spectrum 1, Fig. 10) is presented together with the model spectra for water and $\mathrm{CO}_{2}$ (spectra 2 and 3, Fig. 10). The presence of $\mathrm{CO}_{2}$ which was observed is associated with the decomposition of side groups on the polymer chains.

The water arises as a result of an intermolecular dehydration reaction (Fig. 11). This dehydration process is related to the formation intermolecular anhydride crosslinks between carboxyl groups of neighbouring polymer chains (chemical cross-linking) [17, 21, 26].

The third and fourth losses of mass are primarily related to the emission of $\mathrm{CO}_{2}, \mathrm{CO}$ and low molecular weight organic compounds (Figs. 12, 14, 15). The IR spectrum extracted at a temperature of $326^{\circ} \mathrm{C}$ (spectrum 1, Fig. 12) is presented together with model spectra for $\mathrm{CO}_{2}$ (spectra 2 and 3, Fig. 12).

Above a temperature of $300{ }^{\circ} \mathrm{C}$, fragmentation of the polyacrylic chains occurred. Additionally, side groups experience breaking of bonds in the poly(acrylic acid) chain in the carboxyl group (Fig. 13).

Within a temperature range of 400 and $464{ }^{\circ} \mathrm{C}$, the release of methane and organic components occurs. Here, 


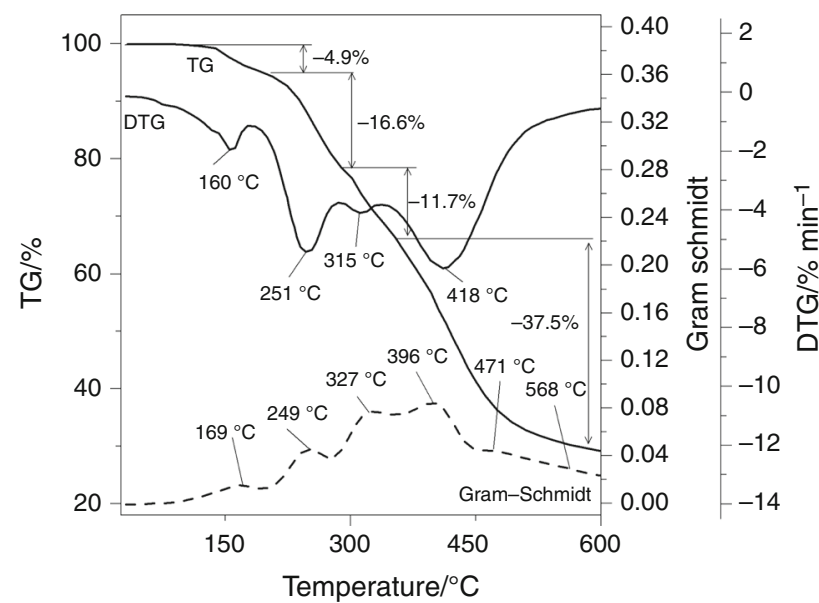

Fig. 7 TG-DTG and Gram-Schmidt curves of PAA/D composition

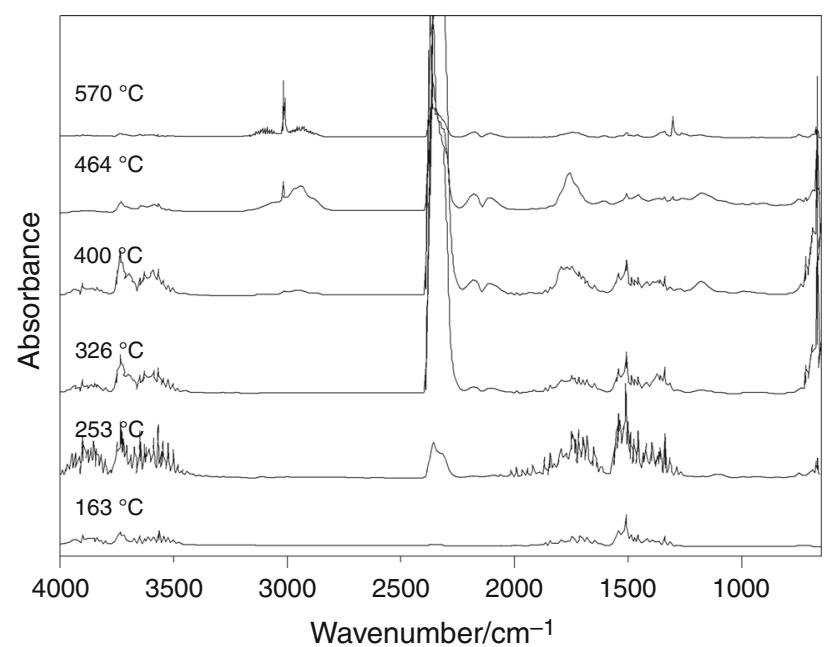

Fig. 8 Extracted IR spectra of the specimen at temperature: 163, 253, $326,400,464$ and $570{ }^{\circ} \mathrm{C}$

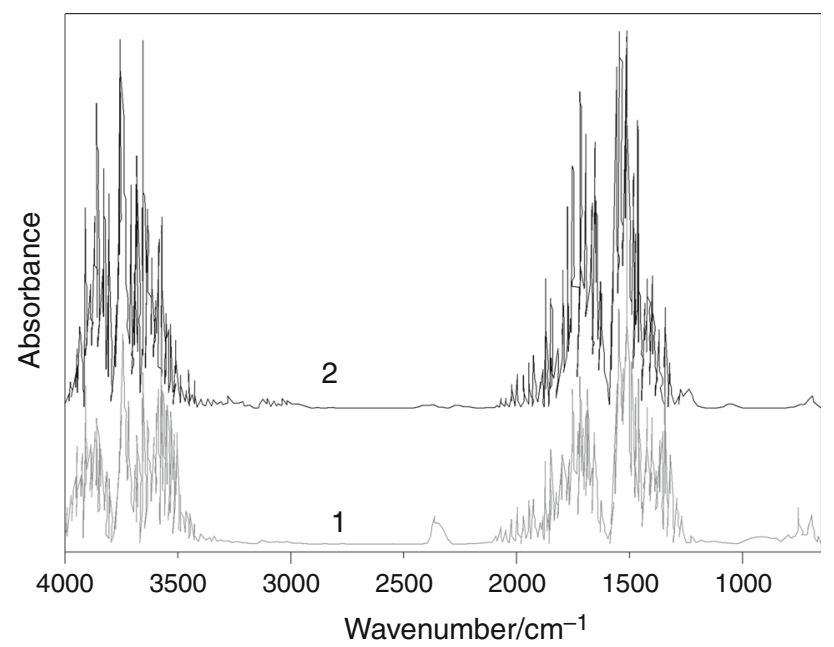

Fig. 9 Comparison of the extracted IR spectrum at $163{ }^{\circ} \mathrm{C}$ (spectrum 1) with the library spectrum of water (spectrum 2)

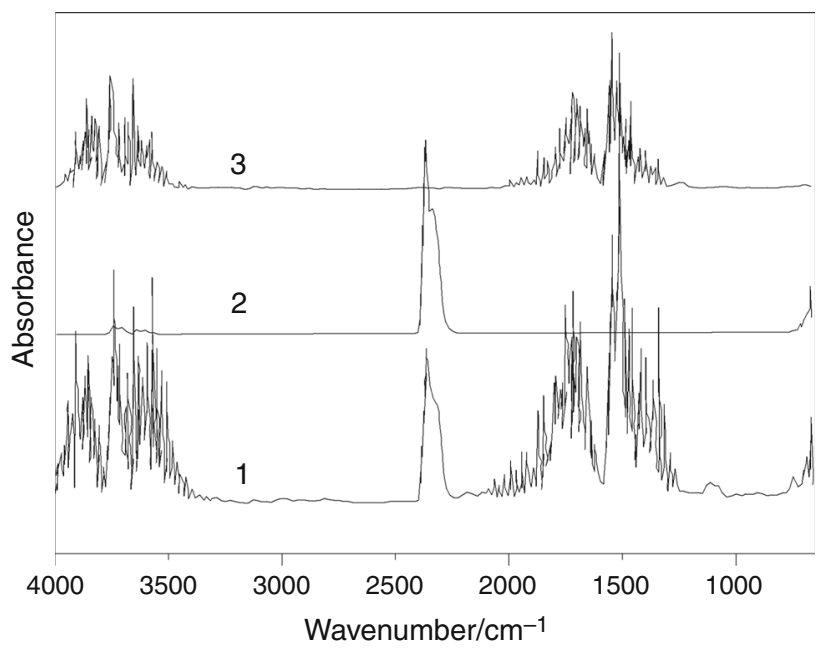

Fig. 10 Comparison of the extracted IR spectrum at $253{ }^{\circ} \mathrm{C}$ (spectrum 1) with the library spectra: (2) $\mathrm{CO}_{2}$ and (3) water

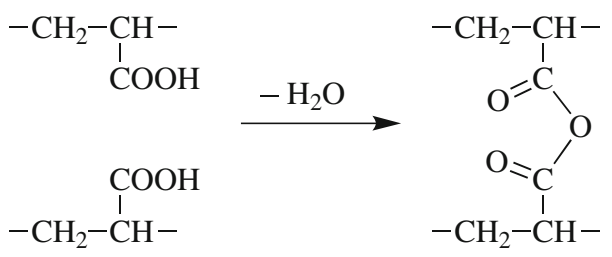

Fig. 11 Intermolecular dehydration reaction

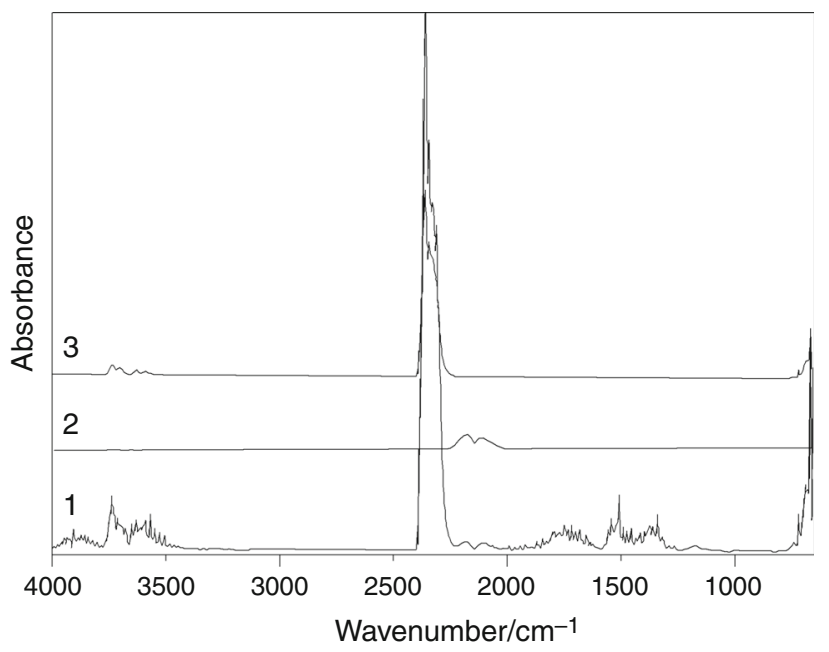

Fig. 12 Comparison of the extracted IR spectrum at $326{ }^{\circ} \mathrm{C}$ (spectrum 1) with the library spectra of $\mathrm{CO}$ (spectrum 2) and $\mathrm{CO}_{2}$ (spectrum 3)

as an example the IR spectrum of 3-methyl-2-cyclopenten1-one is shown in Fig. 14. Thermal degradation of PAA/D is also associated with the decomposition of weak $\mathrm{C}-\mathrm{O}-\mathrm{C}$ bonds present in the glycosidic bond (dextrin), as well as with the formation of oligomeric radicals, which undergo further decomposition forming radicals with even shorter 
Fig. 13 Diagram of degradation in the poly(acrylic acid)

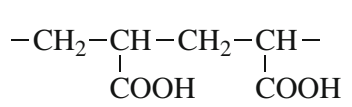

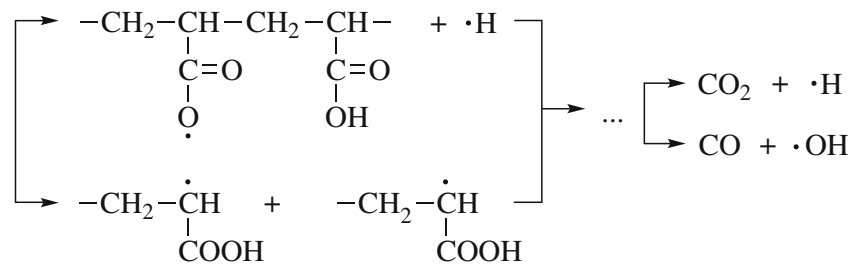

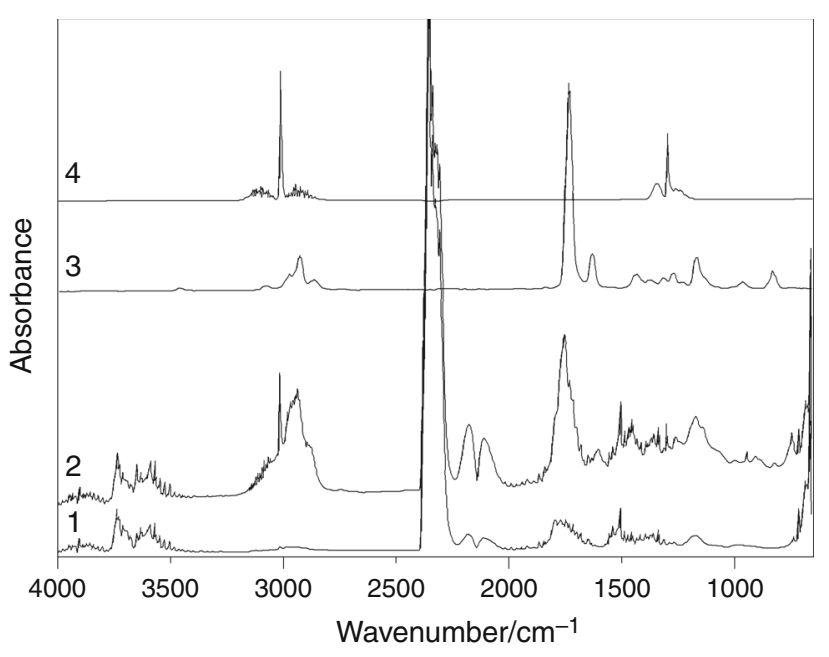

Fig. 14 Comparison of the extracted IR spectrum at: $400{ }^{\circ} \mathrm{C}$ (spectrum 1), $464{ }^{\circ} \mathrm{C}$ (spectrum 2) and with the library spectra of: (3) 3-methyl-2-cyclopenten-1-one, (4) methane

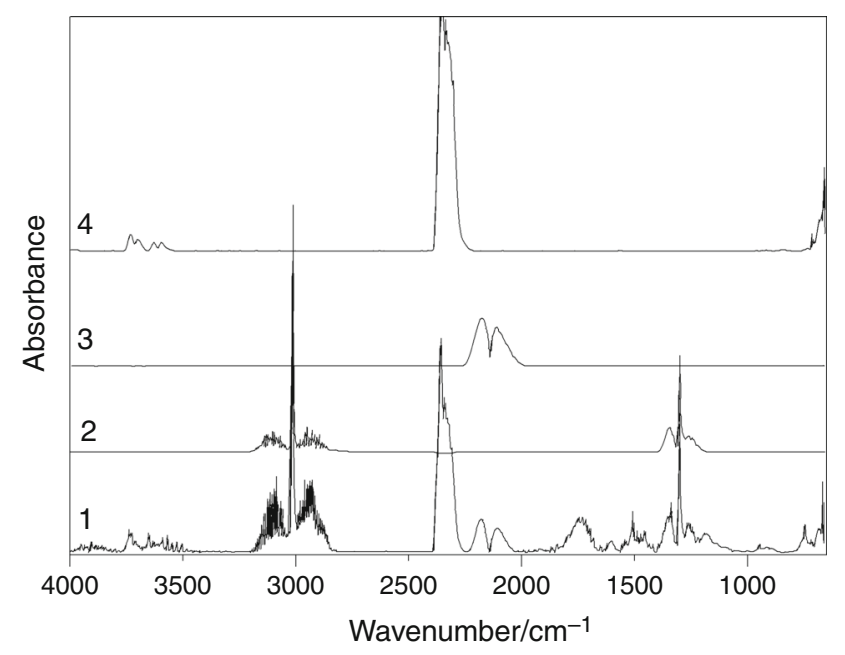

Fig. 15 Comparison of the extracted IR spectrum at $570{ }^{\circ} \mathrm{C}$ (spectrum 1) with the library spectra of: (2) methane, (3) $\mathrm{CO}$ and (4) $\mathrm{CO}_{2}$

chains. For this reason, are formed cyclic ketones (3methyl-2-cyclopenten-1-one) [18-20].

At temperature $570{ }^{\circ} \mathrm{C}$ methane, $\mathrm{CO}$ and $\mathrm{CO}_{2}$ can still be detected. In Fig. 15, the IR spectrum extracted at $570{ }^{\circ} \mathrm{C}$ (spectrum 1) is presented together with the library spectra of methane, $\mathrm{CO}$ and $\mathrm{CO}_{2}$ (spectra 3 and 4).

\section{Conclusions}

The comprehensive thermal analysis conducted in this study (TG-DSC, TG-MS, TG-IR) permits us to determine the temperatures below which PAA/D polymer compositions do not experience thermal degradation, undergoing only reversible changes, meaning that they do not lose their binding properties. The information obtained is essential in regard to the optimisation of conditions in the hardening process using conventional heating methods, and using microwave radiation in the polymer binder-matrix system, as well as in the context of the process of pouring molten metal into the mould. Moreover, the use of coupled TG-MS and TG-IR methods allows us to predict the gaseous products of the degradation of polymer compositions, an important piece of information that addresses to environmental concerns regarding the emission of gaseous substances during the casting process, i.e. at the moment of contact between the components of the hardened mould and the molten metal.

Open Access This article is distributed under the terms of the Creative Commons Attribution 4.0 International License (http://crea tivecommons.org/licenses/by/4.0/), which permits unrestricted use, distribution, and reproduction in any medium, provided you give appropriate credit to the original author(s) and the source, provide a link to the Creative Commons license, and indicate if changes were made.

\section{References}

1. Zhou X, Yang J, Su D, Qu G. The high-temperature resistant mechanism of $\alpha$-starch composite binder for foundry. J Mater Process Technol. 2009;209:5394-8.

2. Kubecki M, Holtzer M, Żymankowska S. Investigations of the Temperature Influence on Formation of Compounds from the BTEX Group During the Thermal Decomposition of Furan Resin. Arch Foundry Eng. 2013;13:85-90.

3. Grabowska B, Szucki M, Suchy JS, Eichholz S, Hodor K. Thermal degradation behavior of cellulose-based materialfor gating systems in iron casting production. Polimery/Polymers. 2013;58:39-44.

4. Wang Y, Huang H, Cannon FS, Voigt RC, Komarneni S, Furness JC. Evaluation of volatile hydrocarbon emission characteristics of carbonaceous additives in green sand foundries. Environ Sci Technol. 2007;41:2957-63.

5. Dungan RS, Kukier U, Lee B. Blending foundry sands with soil: effect on dehydrogenase activity. Sci Total Environ. 2006;357:221-30. 
6. Ahamad T, Alshehri SM. Thermal degradation and evolved gas analysis of thioureaformaldehyde resin (TFR) during pyrolysis and combustion. J Therm Anal Calorim. 2012;109:1039-47.

7. Naro RL. Battling the elusive lustrous carbon defect. Mod Cast. 2003;5:32-5.

8. Chakherlou TN, Mahdinia YV, Akbari A. Influence of lustrous carbon defects on the fatigue life of ductile iron castings using lost foam process. Mater Des. 2011;32:162-9.

9. Grabowska B, Holtzer M, Dańko R, Górny M, Bobrowski A, Olejnik E. New BioCo binders containing biopolymers for foundry industry. Metalurgija. 2013;52:47-50.

10. Grabowska B, Sitarz M, Olejnik E, Kaczmarska K, Tyliszczak B. FT-IR and FT-Raman studies of cross-linking processes with $\mathrm{Ca}^{2+}$ ions, glutaraldehyde and microwave radiation for polymer composition of poly(acrylic acid)/sodium salt of carboxymethyl starch-In moulding sands, Part II. Spectrochim Acta Part A Mol Biomol Spectrosc. 2015;151:27-33.

11. Grabowska B, Sitarz M, Olejnik E, Kaczmarska K. FT-IR and FT-Raman studies of cross-linking processes with $\mathrm{Ca} 2+$ ions, glutaraldehyde and microwave radiation for polymer composition of poly(acrylic acid)/sodium salt of carboxymethyl starch-Part I. Spectrochim Acta Part A Mol Biomol Spectrosc. 2015;135:529-35.

12. Fox JT, Cannon FS, Brown NR, Huang H, Furness JC. Comparison of a new, green foundry binder with conventional foundry binders. Int J Adhes Adhes. 2012;34:38-45.

13. Grabowska B, Malinowski P, Szucki M, Byczyński Ł. Thermal analysis in foundry technology. $\mathrm{J}$ Therm Anal Calorim. 2016;126:245-50.

14. Pielichowski J, Pielichowski K. Application of thermal analysis for the investigation of polymer degradation processes. J Therm Anal. 1995;43:505-8.

15. Jelínek P, Buchtele J, Fiala J. Forms of pyrolytic carbon ensuing on thermal degradation of coal and carbonaceous additives. Acta Metall Slovaca. 1999;5:112-8.
16. Zhang H, Zhao H, Zheng K, Li X, Liu G, Wang Y. Diminishing hazardous air pollutant emissions from pyrolysis of furan no-bake binders using methanesulfonic acid as the binder catalyst. J Therm Anal Calorim. 2014;116:373-81.

17. Lattimer RP. Pyrolysis mass spectrometry of acrylic acid polymers. J Anal Appl Pyrolysis. 2003;68-69:3-14.

18. Lluch AV, Felipe AM, Greus AR, Cadenato A, Ramis X, Salla JM, et al. Thermal analysis characterization of the degradation of biodegradable starch blends in soil. J Appl Polym Sci. 2005;96:358-71.

19. Lawal OS, Lechner MD, Kulicke WM. The synthesis conditions, characterizations and thermal degradation studies of an etherified starch from an unconventional source. Polym Degrad Stab. 2008;93:1520-8.

20. Tudorachi N, Lipsa R, Mustata FR. Thermal Degradation of Carboxymethyl Starch -g-Poly (lactic acid) Copolymer by TGFTIR-MS Analysis. Ind Eng Chem Res. 2012;51:15537-45.

21. McNeill IC, Sadeghi SMT. Thermal stability and degradation mechanisms of poly(acrylic acid) and its salts: part 1-Poly(acrylic acid). Polym Degrad Stab. 1990;29:233-46.

22. Dubinsky S, Grader GS, Shter GE, Silverstein MS. Thermal degradation of poly(acrylic acid) containing copper nitrate. Polym Degrad Stab. 2004;86:171-8.

23. NIST chemistry webbook standard reference database number 69 . 2011. http://webbook.nist.gov/chemistry.

24. Bednarek P, Szafran M. Thermal decomposition of monosaccharides derivatives applied in ceramic gelcasting process investigated by the coupled DTA/TG/MS analysis. J Therm Anal Calorim. 2012;109:773-82.

25. Šimkovic I, Jakab E. Thermogravimetry/mass spectrometry study of weakly basic starch-based ion exchanger. Carbohydr Polym. 2001;45:53-9.

26. Greenberg AR, Kamel I. Kinetics of anhydride formation in poly(acrylic acid) and its effect on the properties of a PAA-alumina composite. J Polym Sci Polym Chem Ed. 1977;15:2137-49. 